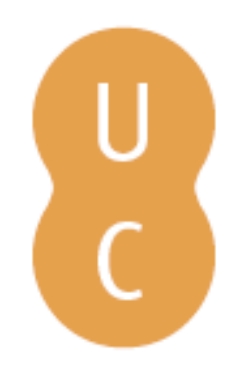

\title{
nombalina
}

\section{Farmácia e saúde em Portugal: de finais do século XVIII a inícios do século XIX}

\author{
Autor(es): $\quad$ Pita, João Rui; Pereira, Ana Leonor
}

Publicado por: Imprensa da Universidade de Coimbra

URL

persistente: $\quad$ URI:http://hdl.handle.net/10316.2/31313

DOI: $\quad$ DOI:http://dx.doi.org/10.14195/978-989-26-0241-7_10

Accessed : $\quad$ 26-Apr-2023 15:52:46

A navegação consulta e descarregamento dos títulos inseridos nas Bibliotecas Digitais UC Digitalis, UC Pombalina e UC Impactum, pressupõem a aceitação plena e sem reservas dos Termos e Condições de Uso destas Bibliotecas Digitais, disponíveis em https://digitalis.uc.pt/pt-pt/termos.

Conforme exposto nos referidos Termos e Condições de Uso, o descarregamento de títulos de acesso restrito requer uma licença válida de autorização devendo o utilizador aceder ao(s) documento(s) a partir de um endereço de IP da instituição detentora da supramencionada licença.

Ao utilizador é apenas permitido o descarregamento para uso pessoal, pelo que o emprego do(s) título(s) descarregado(s) para outro fim, designadamente comercial, carece de autorização do respetivo autor ou editor da obra.

Na medida em que todas as obras da UC Digitalis se encontram protegidas pelo Código do Direito de Autor e Direitos Conexos e demais legislação aplicável, toda a cópia, parcial ou total, deste documento, nos casos em que é legalmente admitida, deverá conter ou fazer-se acompanhar por este aviso.

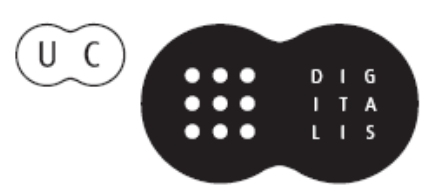




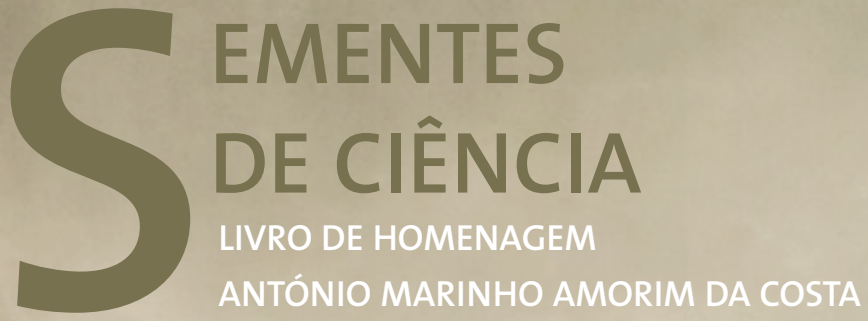

Sebastião J. Formosinho Hugh D. Burrows EDITORES 
João Rui Pita

Professor da Faculdade de Farmácia; Investigador do CEIS20-Universidade de Coimbra.

Email:jrpita@ci.uc.pt

Ana Leonor Pereira

Professora da Faculdade de Letras; Investigadora do CEIS20-Universidade de Coimbra.

Email:aleop@ci.uc.pt

$\mathrm{X}$.

Farmácia e Saúde em Portugal

De finAIS DO SÉculo XVIII A INÍ́cIOS DO SÉculo XIX

Ao nosso Amigo Prof. Doutor A.M. Amorim da Costa

Introdução

Os autores apresentam as principais inovações científicas no domínio da farmácia e dos medicamentos em Portugal no início do século XIX e avaliam as práticas farmacêuticas mais relevantes na época e a sua aplicação a algumas das preocupações de saúde mais significativas. Dão a conhecer alguns dos resultados de uma investigação realizada em fontes manuscritas e impressas que versa a produção medicamentosa na botica do Hospital Escolar da Universidade de Coimbra, a medicação inserta na farmacopeia oficial, a aplicação da moderna química de Lavoisier à medicina (em particular à higiene pública), a vacinação contra a varíola e sua divulgação em Portugal, e a temática em sentido largo da higiene pública em Portugal ${ }^{1}$.

1. A ciência das drogas e dos medicamentos em Portugal no início do século XIX

A reforma pombalina da Universidade de 1772 dinamizou os estudos da arte farmacêutica na Universidade de Coimbra. Criou o Dispensatório Farmacêutico do Hospital Escolar que servia para a produção de medicamentos destinados a doentes do Hospital e a doentes externos e, simultaneamente, 
era o local de ensino farmacêutico para os alunos de medicina e do curso de boticários instituído pela referida reforma.

Vários professores da Faculdade de Medicina legaram-nos, em finais do século XVIII e no início do século XIX, obras relevantes. José Francisco Leal (1744-1786), médico que estagiou em centros de ensino e investigação da Europa, foi o primeiro lente da cadeira de Matéria Médica e Farmácia da Faculdade de Medicina de Coimbra após a reforma de Pombal. Trabalhou com Van Swieten que era discípulo da escola holandesa de Leiden, dirigida por Boerhaave. José Francisco Leal conhecia os avanços estrangeiros em matéria farmacêutica e não hesitou em dar as aulas de farmácia aos seus alunos baseado nas lições de Baumé, uma das referências maiores da farmácia europeia. Escreveu uma obra que nunca publicou, mas que foi dada à estampa por Manuel Joaquim Henriques de Paiva: as Instituições ou Elementos de Farmacia (Lisboa, Officina de António Gomes, 1792). Encontra-se aí bem patente uma das principais preocupações doutrinais da farmácia: a questão de saber se deveria ser galénica ou química. Leal defendia que a farmácia era simultaneamente galénica e química, não fazendo sentido a existência de uma divisão entre as duas, algo que originou forte polémica em muitos países europeus.

Outro vulto que se destacou em finais do século XVIII e início do século XIX foi Francisco Tavares (1750-1812). Professor da Faculdade de Medicina da Universidade de Coimbra, médico e físico-mor. É autor de diversos trabalhos sobre matéria médica, farmácia e hidrologia médica, trabalhos marcantes na época. Foi o autor da primeira farmacopeia oficial portuguesa. Publicou obras como De pharmacologia libellus academicis praelectionibus accomadodatus (1786), Medicamentorum sylloge propriae pharmacological exempla sistens in usum academicarum praelectionum (1787), das quais resultou a primeira farmacopeia oficial portuguesa, publicada em 1794, a Pharmacopea Geral. Contudo, não se tratou de uma junção simples das duas obras, mas antes de uma adaptação selectiva e crítica. Em 1809, Francisco Tavares publicou a Pharmacologia, obra que pretendia substituir a farmacopeia de 1794, porque se mantinha em vigor embora desactualizada. No entanto, mesmo as edições / reimpressões que vieram a seguir, 1822, 1823 e 1824 em nada beneficiaram a obra. Em 1791 Francisco Tavares publicou as Advertências sobre os abusos, 
e legitimo uso das águas minerais das Caldas da Rainha. Em 1799, deu a lume Descrição de um feto bumano monstruoso nascido em Coimbra no dia 28 de Novembro de 1791, trabalho publicado nas Memorias de Mathematica e Phisica da Academia Real das Sciencias de Lisboa, 2, 1799, pp. 296-305. Ainda em 1799 publicou Resultado das observações feitas no hospital real da inoculação das bexigas nos anos de 1796, 1797 e 1798 e, em 1802, Observações e reflexões sobre o uso proveitoso e saudável da quina na gôta. Esta é uma das suas obras mais conhecidas a nível mundial. Houve traduções do seu texto para francês e inglês. Joseph Adams fez a tradução da obra e publicou-a no Jornal médico e físico de Londres (London Medical and Physical Journal) 66, 1804; nos Anais de medicina de Edimburgo a obra de Tavares foi publicada por Duman; em França, o Dicionário de medicina (1836) refere a obra de Francisco Tavares, ao abordar a gôta; Alphonse Le Roy incluiu, na sua obra Manuel des goutteux et des rbumatiques (1803?), a tradução da obra de Francisco Tavares, referindo a sua importância; o Dicionário de terapêutica de Szerleski refere, também, a importância da obra de Francisco Tavares. Em 1810, Francisco Tavares publicou Manual de gotosos e de rheumaticos para uso dos proprios enfermos, no qual efectua uma nova abordagem do tema após o trabalho publicado em 1802, Observações e reflexões sobre o uso proveitoso e saudável da quina na gôta. Em 1810, Francisco Tavares publicou Instrucções e cautelas práticas sobre a natureza, diferentes espécies, virtudes em geral e uso legítimo das águas minerais, principalmente de Caldas de certo modo um prolongamento actualizado da obra que havia publicado em 1791 - Advertencias sobre os abusos e legitimo uso das aguas mineraes das Caldas da Rainha. Em 1829 surgiu uma edição póstuma da Pharmacologia.

Um outro nome a referir na transição do século XVIII para o século XIX é o de Manuel Joaquim Henriques de Paiva, grande difusor das mais recentes ideias médicas, químicas e farmacêuticas. Foi mestre do Laboratório Químico da Faculdade de Filosofia da Universidade de Coimbra. Em Lisboa exerceu clínica e foi tradutor e autor de textos médicos, químicos, farmacêuticos, agrícolas e outros. Teve alguns cargos relevantes na administração médica portuguesa. Contudo, a sua simpatia com os franceses e a sua condição de liberal e de membro da maçonaria levaram-no a sair para o Brasil, de onde tinha vindo, tendo participado no movimento de independência. Escreveu entre várias obras: 
Curso de medicina theorica e pratica destinado para os cirurgiões que andam embarcados, ou que não estudaram nas Universidades (1792); Elementos de Chimica e Pharmacia (1783); Philosophia chimica, ou verdades fundamentais da Chimica moderna dispostas em nova ordem por A.F. Fourcroy (1801; 2. a ed. 1816); Preservativo das bexigas ou historia da vaccina (1801; 1806).

Refiram-se ainda, entre outras obras de interesse para a problemática farmacêutica, os trabalhos seguintes: de A.J. Sousa Pinto, farmacêutico de Lisboa, por exemplo, Elementos de Pharmacia, Chymica, e Botanica para uso dos principiantes (1805); Pharmacopea chymica, médica, e cirurgica (1805) e Materia Medica distribuida em classes e ordens segundo os seus effeitos (1813). Entre 1833 e 1834 foi publicada por B.J.O.T. Cabral a Pharmacopea das Pharmacopeas nacionaes e estrangeiras (2 vols.). Em 1819 saiu a Pharmacopea Naval e Castrense, de Jacinto Costa. Em 1825 Jerónimo Joaquim de Figueiredo publicou a Flora pharmaceutica e alimentar portugueza.

Para além da dimensão botânica, muitas obras farmacêuticas baseavamse na problemática química. Com efeito, para preparar os medicamentos eram necessários conhecimentos botânicos e químicos. A revolução química operada em finais do século XVIII teve consequências capitais no mundo da farmácia e do medicamento. Um dos modos de avaliar a actualização científica da farmácia consiste em verificar a adesão de um cientista, de um profissional ou de uma obra à revolução química. Em Portugal houve iniciativas notáveis na recepção da química de Lavoisier, designadamente no Laboratório Químico da Universidade de Coimbra, onde se se realizaram trabalhos experimentais que tinham por base as experiências de Lavoisier. Tomé Rodrigues Sobral e Vicente Seabra, professores da Faculdade de Filosofia de Coimbra, protagonizaram este novo experimentalismo químico, no início do século XIX, no Laboratório Químico da Universidade de Coimbra.

2.A publicação e a vigência da primeira farmacopeia oficial portuguesa:

Pharmacopeia Geral (1794)

Um dos aspectos mais relevantes da farmácia portuguesa da transição do século XVIII para o século Xıx foi a publicação em 1794 da primeira 
farmacopeia oficial portuguesa: a Pharmacopeia Geral, escrita por Francisco Tavares. Vigorou até 1835, quando foi publicada a segunda farmacopeia oficial portuguesa, o Codigo Pharmaceutico Lusitano, da autoria de A.A.Silveira Pinto. A publicação de uma farmacopeia oficial é uma questão farmacêutica, médica e de saúde pública. Trata-se, muito resumidamente, de colocar em livro oficial um conjunto de drogas e de medicamentos que deveriam ser prescritos pelos médicos e produzidos pelos boticários. Em suma, o livro indicava os medicamentos oficiais, a bem da saúde pública e da defesa do doente, como por diversas vezes se escreveu. A publicação de farmacopeias oficiais era um movimento internacional. Reflectia a tomada de consciência de que o Estado tem um papel tutelar na problemática dos medicamentos e das prescrições médicas. Portugal aderiu bem a este processo internacional de normalização. Contudo, se o nosso foi um dos países que teve desde cedo uma farmacopeia oficial (outras, que circulavam no país, não eram oficiais), o facto é que essa farmacopeia permaneceu no tempo sem qualquer revisão, tornando-se rapidamente obsoleta. Mais: quando foi publicada já estava ultrapassada e, como referimos, as edições seguintes não sofreram as modernizações exigíveis. Ainda assim, a Pharmacopeia Geral foi uma obra de referência, fornecendo-nos uma ideia do arsenal terapêutico oficial em finais do século XVIII e no início do século XIX. A Pharmacopeia Geral foi impressa na Regia Oficina Tipográfica. Pelos Estatutos pombalinos da Universidade de Coimbra era obrigação desta instituição fazer publicar a obra.

A Pharmacopeia Geral está dividida em dois volumes escritos em português. No primeiro volume, nos "conhecimentos preliminares" o autor começa por caracterizar a actividade farmacêutica. Francisco Tavares, definindo-a como a parte da química que trata do estudo, colheita, conservação das drogas e preparação dos medicamentos isto é: "Eleição, colheita, conservação, ou reposição dos medicamentos, na sua preparação, mistura, ou composição" Tavares fala indiferentemente de farmácia ou arte farmacêutica, sublinhando que não deve haver distinção entre farmácia galénica e farmácia química pois toda a química tem interesse na preparação dos medicamentos, com excepção das operações que são "puramente mecânicas"3. Na farmacopeia inscrevem-se os utensílios e os recipientes utilizados na preparação de medicamentos: alambiques de cobre estanhado, de estanho, de barro, de 
vidro; almofarizes de bronze, de ferro, de pedra, de vidro, de marfim, e de chumbo, com suas mãos da mesma matéria, e de pau forte; aludeis de vidro, de barro, de estanho; balanças de diferentes tamanhos; cadinhos de barro vidrados, e não vidrados e de molibdena; caixas de pau, ou bocetas; coadores de lã, linho, e papel pardo; colheres de pau, vidro, e metais; cucurbitas de cobre estanhado, de vidro, e de barro vidrado, e não vidrado; escumadeiras; espátulas de vidro, pau, marfim, latão, e ferro; fornos, ou fornalhas de várias castas, e sobretudo o de Baumé; funis de várias castas, os de vidro com preferência; garrafas de diferentes grandezas, e qualidades; imprensa; limas de diversa grossura; lutos (a); panelas de ferro, barro, cobre estanhado, e de folha de Flandres; peneiros, mais, e menos finos, de seda, e de cabelo; pedra de preperar, e sua moleta; retortas, simples, e com tubo; tachos de vidro de várias grandezas, e de matéria diversa; tigelões, e tigelas de barro, de vidro e metais; vasos para banho de areia, e para banho de Maria. Deve adiantar-se que nos lutos indica-se que os mais usados são: a) "de bexiga ou tripas molhadas"; b) "cal viva com clara de ovo"; c) "goma de trigo, ou farinha em massa posta em tiras de pano, ou papel; d) "uma parte de barro, e três de carvão moído,e amassados com água"; e) "três partes de barro comum vermelho com uma de zarcão"; f) "uma parte de zarcão, duas de barro, e uma de areia em pó misturados com água”; g) "dez partes de barro em pó, e peneirado, duas de fezes d'ouro unidas com cabelo miudamente cortado, e sangue de boi”.

Em seguida, a farmacopeia debruça-se sobre os pesos e medidas utilizados em farmácia. As unidades adoptadas são as então universalmente aceites. As unidades de peso eram: Grão (corresponde a 1 grão de trigo ou de cevada); Escrópulo (corresponde a 24 grãos); Oitava (corresponde a 3 escrópulos); Onça (corresponde a 8 oitavas); Libra (corresponde a 12 onças); Manípulo ou mancheia ou mão cheia (corresponde a 3 oitavas, ou 3 pugilhos ou quanto uma mão pode apanhar); Pugilho (corresponde a 1 oitava ou a quanto se pode apanhar entre os dedos polegar, indicador e maior); Fascículo ou Molhada (o que cabe debaixo do braço). As unidades de medida inscritas eram: Canada (equivale a 4 libras); Libra ou quartilho (equivale a 12 onças); Onça ( equivale a 8 oitavas); Gôta (equivale a 1 grão ponderal); Colher (equivale a 0,5 onça). Tanto nas medidas ponderais como 
nas unidades de volume, determinava-se a existência de meias unidades para concretizar aspectos específicos da prática galénica. As unidades de medida tinham uma simbologia própria. Depois, a farmacopeia de 1794 trata da Eleição, colheita, reposição, e duração dos simplices.

A segunda parte do primeiro volume da farmacopeia dedica-se às preparações farmacêuticas. O autor refere com pormenor as operações farmacêuticas utilizadas na obtenção de preparações farmacêuticas: com a Pulverização (obtêm-se Pós compostos); Expressão (Sumos e óleos espremidos); Depuração ou purificação de líquidos (Destilados); Evaporação (Sumos espessos, arrobes e polpas); Dissolução (Dissoluções); Cristalização (Sais); Precipitação (Precipitado, magistério ou enxofre); Extracção (Extractos líquidos, infusões, vinagres, vinhos e óleos por infusão, cozimentos, tinturas, essencias, elixires e bálsamos cheirosos líquidos); extractos sólidos (1. aquosos gomosos, mucilaginosos e geleias; 2. espirituosos ou resinosos; 3. aqueo-espirituosos ou gomoso-resinosos); Destilação (Águas destiladas simples e compostas; espíritos inflamáveis; águas destiladas espirituosas ; óleos essenciais destilados ; espíritos e sais alcalinos voláteis; óleos empireumáticos destilados; espíritos ácidos; espíritos ácidos adoçados); Sublimação (Sublimados e flores); Calcinação (Pós); Fusão e vitrificação (Vidros).

A terceira parte do primeiro volume, subordinada ao título "Da Mistura, ou composição dos medicamentos”, aborda a temática dos medicamentos compostos, os que resultam da "união de diversos medicamentos simplices (...) ou da combinação de medicamentos já compostos” . O autor sistematiza, quanto à consistência, três grandes grupos medicamentosos: sólidos, líquidos e pastosos ${ }^{5}$ ou, usando a terminologia da época, "líquida", "mole" e "dura ou seca”. As formas medicamentosas descritas por Francisco Tavares são as seguintes: Sabões; Espécies; Xaropes, Méis, Oximéis e Loochs; Emulsões; Misturas; Conservas; Electuários, confeições e bolos; Pílulas; Trociscos, pastas ou pastilhas, mórsulos, rótulas ou rodinhas; Cataplasmas; Linimentos; Unguentos e pomadas; Emplastros, cerotos e velinhas. O autor percorre cada forma por si não fazendo referência à sua composição, remetendo essa matéria para o segundo volume da farmacopeia. Na terceira parte, o autor não faz qualquer tipo de distinção entre medicamentos magistrais e medicamentos oficinais. Tavares junta todos os medicamentos, dando 
uma definição de cada um deles, a técnica de preparação, as operações farmacêuticas adequadas, bem como as variações a ter sempre presentes. Refere, também, as condições de aplicação do medicamento (uso externo, uso interno ou outro) e aborda os constituintes fundamentais da preparação. A terminar o primeiro volume, inscreve três tabelas com utilidade prática na técnica laboratorial. A primeira intitula-se "Da diversa quantidade dos vários sais de uso medicinal, que se dissolve numa dada quantidade de água, sendo o calor da atmosfera de 50 graus do Termómetro de Farenheit, conforme as observações de SPIELMANN"; a segunda trata "Das afinidades das diferentes substâncias, segundo Lewis"; a terceira consta de uma "Lista das abreviaturas, e caracteres químicos”.

O segundo volume da obra trata dos "medicamentos simplices, preparados e compostos", ou seja, as matérias-primas necessárias à preparação dos medicamentos. Inscreve, ainda, um formulário onde o autor trabalha com as drogas devidamente identificadas e inscritas e com as técnicas farmacêuticas insertas no primeiro volume. Também faz uma inventariação de um conjunto de fórmulas consideradas de reconhecida eficácia terapêutica. O autor salienta que apenas inscreveu fórmulas oficinais pois são aquelas que no seu entender já foram consagradas como eficazes, sendo de maior conservação no tempo quando comparadas com as formas magistrais. Estas também eram mais subjectivas pois dependiam muito do critério do médico e, por isso, não constavam, propositadamente, da farmacopeia. O segundo volume da farmacopeia está dividido em duas partes. A primeira trata das matérias-primas e intitula-se "Matéria Farmacêutica, ou dos medicamentos simplices" e mais não é do que um conjunto de monografias das diversas drogas úteis na preparação medicamentosa, seriadas por ordem alfabética, independentemente da sua origem, tal como era tradição nas farmacopeias europeias do tempo ${ }^{6}$. Em todas se segue o mesmo plano de descrição: o nome comum, outros nomes comuns por que pode ser conhecida, a parte utilizada se se tratar de um vegetal, o nome latino, a classificação lineana (na maioria dos casos; noutros não se conhece a espécie); o habitat (fundamentalmente no caso dos vegetais); a forma (caso dos vegetais); e, ainda, algumas propriedades, como cor, o cheiro e o sabor. Não se fazem, contudo, considerações de natureza terapêutica, pelo que aquele registo se 
deve considerar sobretudo como uma minuciosa flora farmacêutica do que propriamente um tratado de matéria-médica.

Na farmacopeia de 1794 são descritos 206 símplices diferentes, distribuídos pelos vários reinos da natureza. As drogas vegetais contam com 168 elementos, seguem-se os produtos de origem mineral e química com 26 elementos e, finalmente, os de origem animal com 12 símplices. No que toca às drogas de origem vegetal, as drogas europeias e da bacia do Mediterrâneo apresentam-se com um total de 114, seguindo-se as de África e Oriente com 30 e as americanas com um total de 24.

Das 206 matérias-primas inscritas na farmacopeia correspondentes aos três reinos da natureza, uma larga maioria já se encontrava descrita na sua obra de 1787. Apenas 11 produtos não constam dela. Isto é, o autor recuperou cerca de $95 \%$ dos símplices referidos e introduziu pela primeira vez as seguintes drogas: ameixa, amora, aveia, bdélio, cinosbastos, dedaleira, erva santa, ouregãos, trevo de água (símplices de origem vegetal), estanho e vinho branco e tinto (drogas de origem mineral e química). Também especifica melhor as quinas e a ipecacuanha que passa a dividir em quina e quina vermelha, e em ipecacuanha e ipecacunaha branca.

No que diz respeito aos medicamentos compostos e preparados, a Pharmacopeia Geral inclui 304. A sua inscrição na obra é feita por ordem alfabética. A metodologia de descrição adoptada é semelhante para todos os produtos e segue a tradição da épocaª . A fórmula é inscrita (qualitativamente e quantitativamente) em português. Depois segue-se o seu modo de preparação com a descrição do modo operatório, não sendo feitas considerações sobre a sua acção terapêutica, tal como aconteceu com a obra de 1787. Por vezes, o autor indica outros nomes pelos quais é conhecido o mesmo medicamento. Francisco Tavares usa a terminologia química pré-lavoisieriana, como acontecera com os seus tratados anteriores de matéria médica e de farmácia, o que é perfeitamente compreensível.

Dos 304 medicamentos preparados e compostos, Tavares recupera 252 do seu Medicamentorum Sylloge. Não encontrámos referências à origem das outras preparações farmacêuticas. Como Francisco Tavares inscreveu no seu tratado de matéria médica e farmácia as fontes do seu formulário, determinámos a base científica que orientou a sua farmacopeia. Assim, 
verificámos que as 252 fórmulas inscritas na Pharmacopeia Geral tiveram origem bibliográfica nas obras ou tratados de farmácia seguintes: Elements de Pharmacie - Baumé, 1773 (4), New Dispensatory - Lewis, 1770 (8), Diccionaire de Chyimie - Macquer, 1778 (2), Ph. Austriaco Provincialis, 1775 (2), Ph Edimburgensis, 1776 (146), Ph. Generalis, 1783 (1), Ph. Londinensis, 1764 (8), Ph. Rossica, 1782 (2), Ph. Rationalis, 1782 (6), Ph. Suecica, 1779 (33), Pharmacia Chirurgica - Plenck, 1775 (6), De Pharmacologia Libellus, 1786 (25), Ph. Londinensis e Ph Rationalis (1), Ph. Londinensis e Ph. Suecica (1), Ph. Londinensis, Ph. Suecica e Ph. Edimburgensis (2), Autores variados s/ identificação da fonte (3). Assim se pode concluir que a Pharmacopeia Geral é uma obra que se encontra suportada bibliografica e cientificamente, em quase 60\%, pela edição aumentada de 1776 da Pharmacopoeia Edimburgensis ${ }^{8}$.

Os medicamentos preparados e compostos inscritos na Pharmacopeia Geral são os seguintes: Águas destiladas (7), Águas destiladas espirituosas (9), Cataplasmas (5), Conservas (8), Cozimentos (11), Dissoluções (14), Electuários, confeições e bolos (5), Emplastros e cerotos (14), Emulsões (4), Espíritos (12), Extractos (24), Infusões (7), Linimentos (4), Misturas (6), Óleos destilados (8), Óleos por infusão (1), Pílulas (11), Polpas e sumos espessos (5), Pós (11), Preparações de antimónio (6), Preparações de chumbo (1), Preparações de ferro (4), Preparações de mercúrio (12), Preparações de prata (1), Preparações de zinco (2), Sabões (2), Sais (18), sumos e óleos por expressão (13), Tinturas e elixires (26), Trociscos (3), Unguentos e pomadas (13), Vinagres medicinais (8), Vinhos medicinais (10), Xaropes, méis, oximéis e loochs (19)9.

3. A botica do Hospital Escolar da Universidade de Coimbra: estudo de caso sobre a produção de medicamentos em Portugal

O estudo de caso que vamos apresentar para o funcionamento de uma botica é o Dispensatório Farmacêutico, que era a Botica do Hospital Escolar. Foi criado o Dispensatório em 1772 pela reforma pombalina da Universidade, mas somente em 1779 entrou em funcionamento em instalações próprias no adaptado Colégio das Onze Mil Virgens ou Colégio de Jesus que havia pertencido à Companhia de Jesus. 
Fizemos um estudo sobre o funcionamento da botica entre 1772 e 1836. O início do seu exercício coincide com a mudança definitiva do Hospital da zona baixa da Cidade de Coimbra para a Couraça dos Apóstolos, junto à Universidade, em Março de 1779. Só a partir deste ano o Dispensatório Farmacêutico foi provido de um boticário. A liderança do Dispensatório estava a cargo do lente de Matéria Médica e Farmácia da Faculdade de Medicina ${ }^{10}$.

O Dispensatório Farmacêutico funcionou de início num espaço significativamente grande. Era uma botica com grande dimensão e que produzia medicamentos em grande escala para doentes do Hospital e para doentes externos. Servia igualmente como local de aulas práticas para os alunos de farmácia e como local de formação para os alunos do curso de boticários O boticário administrador do Dispensatório exercia funções administrativas e pedagógicas porque tinha a seu cargo a formação prática dos candidatos a boticários. Em ambas as funções estava, porém, sujeito à tutela do lente de Matéria Médica e Farmácia que era, em última análise, o responsável pelo funcionamento global do Dispensatório.

A abordagem da produção medicamentosa do Dispensatório Farmacêutico na cronologia apontada revelou, antes de mais, que este estabelecimento passou por fases distintas no que concerne à política de aquisição de drogas, política que tinha a ver com a disponibilidade financeira da instituição e não com os seus administradores. Neste particular, verifica-se que o fornecimento de material de vidro era feito a partir da fábrica Stephens na Marinha Grande e que o principal fornecedor de drogas e utensílios ao Dispensatório era José Ribeiro da Costa, droguista no Porto. Também há casos em que as drogas eram fornecidas por droguistas espanhóis.

Através do levantamento que realizámos de 1954 receitas médicas, compreendendo, na generalidade, mais do que um medicamento composto, verificámos que, na sua maioria, se destinavam a pessoas relacionadas com a Universidade, com muita frequência professores ou funcionários. Registase uma assinalável sintonia entre o que era formulado na literatura médica e o que era fabricado no Dispensatório.

No que diz respeito à produção medicamentosa (entre as receitas que estudámos), concluimos que eram as pílulas a forma farmacêutica mais pretendida (cerca de 40,9\%), seguindo-se os pós (17,9\%) e os bolos 
(10,9\%) e, a certa distância, os electuários (8,5\%). Quanto às drogas, prescreviam-se fármacos de origem animal, vegetal e mineral e química, não se encontrando qualquer produto de origem extractiva. Das drogas inventariadas, perto de $80 \%$ provinham do reino vegetal, seguindo-se as de origem mineral e química com cerca de $14 \%$ e as animais com aproximadamente $7 \%$. Entre as drogas vegetais, predominavam as europeias e da bacia do mediterrâneo com cerca de 65\% da variedade prescrita, contra os $17,5 \%$ de cada uma dos outros grupos de drogas (africanas e orientais e, ainda, americanas). Quantitativamente, as drogas americanas eram as mais prescritas (40,7\%), seguindo-se as europeias e da bacia do Mediterrâneo $(36,4 \%)$ e as africanas e orientais (22,9\%). Só a quina ocupava cerca de $22,6 \%$ da totalidade das drogas prescritas. As drogas de origem americana eram vendidas, frequentemente, por droguistas espanhóis, que as apresentavam em melhores condições de consumo e a mais baixo preço. Também no que respeita à variedade de fármacos constantes das 1954 receitas analisadas, havia uma clara aproximação ao texto da farmacopeia oficial de 1794, figurando neste 63,6\% das drogas animais, 66,7\% das minerais e químicas, 90,5\% das vegetais americanas, $81 \%$ das vegetais africanas e orientais e $73,1 \%$ das europeias e da bacia do mediterrâneo. No que concerne à quantidade de drogas prescritas, a aproximação à farmacopeia era ainda mais clara: da quantidade total de drogas prescritas constavam do texto oficial 81,5\% das drogas de origem animal, 95,9\% das drogas de origem mineral e química, 98,6\% das africanas e orientais, $89,1 \%$ das europeias e da bacia do mediterrâneo e 99,4\% das americanas. Quanto aos medicamentos preparados e compostos, os mais prescritos foram os seguintes: o grupo dos xaropes, méis, oximéis e loochs deteve 16,3\%, as águas destiladas $15,2 \%$ e os sais $13,5 \%$. Nota-se, também aqui, uma significativa adesão ao que se encontrava estipulado na farmacopeia de 1794: mais de 94\% das águas destiladas e cerca de 92\% dos sais e 65,8\% dos xaropes encontravam-se inscritos naquela obra. Aliás, dos 3171 medicamentos preparados e compostos que figuravam nas citadas receitas médicas, apenas 622 não constavam da Pharmacopeia Geral, o que significa que cerca de $80 \%$ da medicação prescrita estava rigorosamente de acordo com aquele texto oficial. A taxa de adesão 
torna-se ainda mais significativa $(86,5 \%)$ quando se atende às datas das receitas e se excluem os 224 medicamentos prescritos antes da publicação da farmacopeia oficial.

Mas é importante sublinhar que o Dispensatório Farmacêutico, aquando das invasões francesas, preparou medicamentos para militares internados, portuguesas e estrangeiros, o que aumentou em grande escala o movimento do Hospital Escolar. Localizámos vários médicos que serviram no exército. Também os serviços farmacêuticos sofreram os efeitos das necessidades acrescidas devido às batalhas e aos conflitos. Mesmo depois das invasões, a continuação do internamento e tratamento de militares levou a um grande consumo de medicamentos do Dispensatório com o respectivo acréscimo de despesas, o que não era compatível para o orçamento do estabelecimento.

O Dispensatório Farmacêutico funcionava, também, como intermediário de distribuição de medicamentos a hospitais militares em várias zonas do país ${ }^{11}$. O Dispensatório era uma grande botica com uma produção e capacidade de fornecimento inigualáveis no contexto nacional da época. Como exemplo, refira-se que o Dispensatório Farmacêutico abasteceu a botica de Almeida em 1801 de acordo com as ordens do físico-mor ${ }^{12}$. Em 24 de Março, 31 de Março e em 16 de Abril de 1801 o Dispensatório Farmacêutico forneceu drogas e utensílios para boticas do exército português no valor de $75 \$ 175$ réis $^{13}$. O mesmo aconteceu em 28 de Abril do mesmo ano com a ordem dada ao Dispensatório para disponibilizar um determinado lote de drogas para as "Boticas do Exercito Portuguez da Repartição da Beira, ou d'Almeida e Vizeu” no valor de 856\$880 réis ${ }^{14}$. Em Junho desse ano foram enviadas para as boticas de Almeida e de Viseu drogas e utensílios no valor de 31\$405 réis ${ }^{15}$; e em 13 de Julho chegou ao Dispensatório um contingente de drogas provenientes de Lisboa, no valor de 21\$215 réis, destinadas a ficarem depositadas no Dispensatório para depois serem distribuídas pelas boticas do exército ${ }^{16}$.

Em 31 de Julho de 1809, o fornecimento de medicamentos foi tão grande que o lente da Faculdade de Medicina, Gramacho da Fonseca, dizia que tal situação era insustentável para o Dispensatório, por duas razões: porque o estabelecimento não tinha possibilidades económicas que suportassem as necessidades de fornecimento; e porque a grande quantidade poderia originar uma deficiência na qualidade da produção. Gramacho da Fonseca 
considerava a situação muito grave e apelava a uma intervenção urgente por quem de direito. Esta representação de Gramacho da Fonseca surgiu algum tempo depois do boticário administrador do Dispensatório, Francisco José de Torres, ter manifestado, também, ao reitor da Universidade de Coimbra as suas dificuldades em virtude do fornecimento de medicamentos a doentes militares pelo Dispensatório Farmacêutico ${ }^{17}$.

A 21 de Junho de $1809^{18}$ Francisco José de Torres voltou a informar que naquela data se continuava, ainda, a facultar os medicamentos aos doentes militares sem ter havido qualquer tipo de solução económica por tal trabalho o que agravava, ainda mais, a economia do Dispensatório Farmacêutico. A 12 de Setembro de 1828, o boticário do Dispensatório Farmacêutico comunicou à Junta da Fazenda da Universidade ${ }^{19}$ que, naquele momento, se achavam extintas as fontes de rendimento daquele estabelecimento farmacêutico e que, ainda, "pela ausencia da maior parte das peçoas que delle se servião, e pelas excessivas despezas precedentemente feitas (...) não se acha actualmente em estado de sustentar a enorme despeza necessaria para sustentar o recetuario de hum hospital de hum grande numero de militares". Neste sentido e para colmatar estas deficiências resolveu a Junta da Fazenda da Universidade, no dia seguinte, destinar $120 \$ 000$ réis para fazer face às despesas mais urgentes.

A preocupação do lente de Matéria Médica e Farmácia e do próprio boticário do Dispensatório, relativamente à economia do estabelecimento, era simples: esgotando-se as drogas, degradando-se aparelhos e utensílios necessários à produção de medicamentos, havia o risco de não haver demonstrações práticas para os alunos de medicina e de farmácia e de se inviabilizar a produção de medicamentos para os doentes do Hospital. O Dispensatório era tutelado, do ponto de vista económico, pela Junta da Fazenda da Universidade e as receitas para este estabelecimento eram escassas já que a entrada de verbas provenientes da venda dos medicamentos eram extremamente reduzidas, sendo enorme o rol dos devedores ${ }^{20}$. Desde o início do funcionamento do Dispensatório Farmacêutico e até ao final de 1825, as dívidas para com o Dispensatório ascendiam a 1595\$395 réis; desta quantia, a administração considerava que 1122 \$385 réis correspondiam a clientes não habituais do Dispensatório, propondo que contra eles houvesse um procedimento activo no sentido da recuperação do dinheiro 
investido. A restante quantia correspondia a dívidas de clientes habituais e que, regularmente, liquidavam as suas $\operatorname{contas}^{21}$. Em Janeiro de 1827 o total das dívidas cifrava-se em 879\$090 réis ${ }^{22}$.

4. A quina: droga maior do início do século XIX. O papel do cientista

\section{Bernardino António Gomes}

A todos os títulos faz sentido destacar, entre as drogas que circularam no início do século XIX, a quina e os seus medicamentos. É um assunto que estudamos há vários anos, em diferentes tipos de fontes. Vimos que no Hospital Escolar era a droga mais receitada. Os seus efeitos terapêuticos eram evidentes. Deu lugar a imensas iniciativas de natureza comercial e, obviamente, de natureza científica.

Dado o interesse das drogas sul-americanas, no início do século XIX, o Governo português teve como objectivo verificar a existência da quina ou de outras plantas com propriedades febrífugas no Brasil. Estavam em causa problemas de ordem comercial, económica e científica. A Universidade de Coimbra, o Hospital Escolar, a Academia das Ciências de Lisboa e o Hospital da Marinha ficaram responsáveis pelo estudo do assunto. Em Lisboa, os trabalhos ficaram a cargo do médico Bernardino António Gomes e, em Coimbra, um dos protagonistas principais na análise das quinas foi Tomé Rodrigues Sobral, professor de química da Universidade de Coimbra. Bernardino António Gomes chegou a conclusões antes de Sobral. Isolou um produto - o cinchonino - que era o primeiro alcalóide extraído da quina. Gomes conseguiu isolar o cinchonino a partir de um extracto alcoólico de quina cinzenta. Obteve pequenos cristais de cinchonino. Para obter o produto Gomes sujeitou a tratamento com potassa as soluções extractivas aquosas de quina que havia preparado. Recristalizou no álcool o precipitado que obteve. Isolou depois os cristais obtidos (a cinchonina) que eram solúveis nos ácidos e que precipitavam na presença de potassa. Estava isolado o primeiro alcalóide da quina — o cinchonino.

A sua descoberta foi envolvida numa enorme polémica. Contudo, apesar de ter descoberto o novo composto, Gomes não verificou de imediato que 
se tratava de um composto com propriedades alcalinas, pensando de acordo com o paradigma da época que referia que no reino vegetal apenas existiam componentes ácidos e neutros. A alcalinidade do novo composto era, para Gomes, devida à potassa que entrava no trabalho químico.

$\mathrm{Na}$ Universidade de Coimbra, José Feliciano de Castilho (Professor da Faculdade de Medicina) não aceitou a descoberta, afirmando ser impossível que Bernardino António Gomes pudesse ter chegado a tais conclusões. A polémica surgiu entre estes dois professores e revelou um conflito de poderes e de saberes pois a descoberta havia sido feita fora da Universidade, a única então existente em Portugal e lider da investigação científica.

No Jornal de Coimbra encontramos grande parte da polémica. Esta só foi atenuada depois de Gomes se ter deslocado a França e ter mostrado os resultados a cientistas franceses que lhe disseram que os seus resultados eram válidos. Laubert e Houton de Labillardière reconheceram a validade do trabalho e dos resultados de Gomes e, assim, foram decisivos para a aceitação da descoberta em Portugal. Gomes detectou o aparecimento de cristais - o cinchonino - e de outras formações de aspecto cristalino que haviam aderido às paredes dos recipientes e que não identificou. Ora estes cristais que Gomes não identificou foram identificados mais tarde, em 1820, por Pelletier e Caventou, em Paris - era o quinino.

Bernardino António Gomes esteve a um passo da maior consagração; indirectamente parece ter obtido o quinino e não conseguiu identificá-lo. O quinino viria a revelar propriedades febrífugas incomparavelmente mais eficazes do que o cinchonino. Entre os trabalhos de Gomes refiram-se "Extracto do ensaio sobre o Cinchonino, e sobre sua influencia na virtude da Quina, e de outras cascas", publicado em O Investigador Portuguez em Inglaterra (1811), "Observações Botanico-Medicas sobre algumas Plantas do Brazil" inserto em Memorias de Mathematica e Physica da Academia Real das Sciencias de Lisboa (1812), "Ensaio sobre o Cinchonino e sobre sua influencia na virtude da Quina, e de outras cascas", publicado em Memorias de Mathematica e Physica da Academia Real das Sciencias de Lisboa (1812). Em 1819, Tomé Rodrigues Sobral publicou "Memoria sobre o principio febrifugo das quinas" no Jornal de Coimbra (1819). Entre outros autores que se preocuparam com a quina refiram-se, José Mariano da Conceição Veloso autor da Quinografia 
portuguesa (1799), José Ferreira da Silva, Observações sobre a propriedade da quina do Brasil (1801), Francisco Tavares que publicou Observações e reflexões sobre o uso proveitoso e saudavel da quina na gôta (1802).

Retomando o estudo de caso do Dispensatório Farmacêutico, uma amostra de cerca de 2000 receitas médicas (duas mil) do Hospital Escolar da Universidade de Coimbra, entre 1772 e 1836, que trabalhámos uma a uma, permite-nos tirar as conclusões seguintes. Relativamente ao tipo de drogas encontrámos: drogas de origem animal, 11 diferentes e um total de 81 vezes prescritas; drogas de origem mineral e química, 22 diferentes e um total de 475 vezes receitadas; drogas de origem vegetal, 120 diferentes e 1915 vezes receitadas. Relativamente à origem geográfica das drogas as da Europa e da bacia do Mediterrâneo são 78; de África e Oriente, bem como da América, encontrámos 21 diferentes para cada um destes dois últimos grupos. As do primeiro grupo surgem prescritas 697 vezes; as de África e Oriente, 439 vezes; as drogas americanas foram receitadas 779 vezes. Entre as drogas americanas mais prescritas a quina surge em primeiro lugar, com um total de 434 vezes. Segue-se a jalapa, receitada 98 vezes; o açúcar branco, 50 vezes; a ipecacuanha, 47 vezes; a salsaparrilha, 33 vezes. E outras drogas, 117 vezes.

Entre os droguistas que forneciam drogas à botica, vários eram espanhóis, sendo de destacar a venda de drogas americanas, em particular a quina. Os droguistas de fora de Coimbra ou mesmo os espanhóis forneciam drogas de melhor qualidade e a mais baixo preço. Encontrámos os nomes dos seguintes droguistas espanhóis: António Pastor (data?, finais do séc. XVIII); Francisco Rodriguez Zimenez (1779); Josef Rodico Machado (1798); Francisco Rodriguez Sanchez (1801).

5. Uma questão de saúde pública: a vacinação jenneriana contra a varíola, a primeira medicação preventiva

Uma das facetas práticas mais visíveis da dinâmica médico-farmacêutica preventiva operada entre finais do século XVIII e inícios do século XIX foi a vacinação contra a varíola introduzida pelo médico escocês Edward Jenner. 
A vacina vinha ao encontro das medidas de política sanitaria que então se operavam e que tinham como elemento prático a prevenção da doença. E isto articulava-se com a estratégia apresentada na obra System einer vollständigen medicinischen polizey (Sistema de uma polícia médica) da autoria do médico vienense Johann Peter Frank. Trata-se da primeira obra de grande fôlego, divulgada em toda a Europa, e ao mesmo tempo um trabalho pioneiro a respeito de diferentes estratégias a adoptar no campo da higiene privada e, também, da higiene pública. O autor defende vivamente o primado duma regulamentação com eficácia e com capacidade para proporcionar às populações a defesa da sua saúde e das condições de vida. A vacinação jenneriana veio controlar a progressão da varíola de um modo muito mais eficaz e seguro do que aquele que se aplicava na época. O trabalho final de Jenner que traduz as suas teorias e práticas a adoptar na prevenção da doença intitula-se An Inquiry into the Causes and Effects of the Variolae Vaccinae. A descoberta de Jenner percorreu rapidamente a Europa e atravessou o Atlântico. A vacinação era uma prática em perfeita sintonia com os ideais do iluminismo. Diminuiu a taxa de mortalidade da Europa, aumentou a esperança de vida, veio contribuir para o vigor físico da população devendo ser aplicada de acordo com medidas político-sanitárias adequadas.

Em Portugal também foi demonstrada a eficácia da técnica da vacinação. Os relatórios da Instituição Vacínica, fundada em 1812 no âmbito da Academia das Ciências de Lisboa para divulgar a vacina e a vacinação indicam que, nos primeiros anos do século XIX, a adesão à prática da vacinação não foi animadora. Como já escrevemos em 1993, na Revista de História das Ideias da Faculdade de Letras da Universidade de Coimbra, "apesar da iniciativa estatal em matéria de higiene pública-privada e apesar da força da lei, nem assim as populações depositaram total confiança na prática vacínica. Não era propriamente o reconhecimento médico, nem o reconhecimento político da necessidade de higienizar a sociedade portuguesa que travava a resolução dos problemas" ${ }^{23}$, mas algo de estruturante da forma mentis portuguesa de então.

O combate em favor da saúde das populações e a dinâmica higienista circulavam em obras que também chegaram a Portugal, como a de André 
Tissot, Avis au peuple sur la santé (1761), que foi traduzida por Henriques de Paiva e publicada em 1796 (3 vols.) sob o título: Avizo ao povo ácerca da sua saude. Henriques de Paiva deixava claro nas suas obras que havia duas regras essenciais: "o valor político da saúde e a sua afirmação através de uma pedagogia eficaz" ${ }^{24}$, sendo um defensor de que a alfabetização da população em termos sanitários era decisiva, tendo sempre presente como meta "a efectivação social do higienismo" 25.

Manuel Joaquim Henriques de Paiva tratou, logo em 1801, de difundir a vacina em Portugal. Mas podemos assinalar muitos outros textos que nos remetem para o interesse crescente da vacinação nos primeiros anos do século XIX, como marca de política sanitaria. Os resultados práticos eram visíveis por todos e com efeitos altamente benéficos na população. Houve alguma polémica como sempre que algo de novo se institucionaliza. Assinalese como voz antagonista a de Heleodoro Jacinto de Araujo, Reflexoens, e observaçoens sobre a pratica da inoculaçaõ da vaccina, e as suas funestas consequencias feitas em Inglaterra (1808) e "Reflexoens e observaçoens sobre a pratica da Inoculaçaõ da vaccina e suas nefastas consequências, feitas em Inglaterra pelo Dr. (...)" (O Investigador Portuguez em Inglaterra 1811 e 1812). Entre outros textos defensores, na sua generalidade, da vacinação jenneriana, assinalem-se, sobretudo até aos anos 20 e como reflexão sobre a vacina e os trabalhos da Instituição Vacínica, de António Almeida, "Annaes vaccinicos de Portugal, ou Memoria Chronologica da Vaccinação em Portugal, desde a sua introdução até o estabelecimento da Instituição Vaccinica da Academia Real das Sciencias de Lisboa" (Historia e Memorias da Academia Real das Sciencias de Lisboa,1816); Inácio António da Fonseca Benevides, "Discurso historico sobre os trabalhos da Instituição Vaccinica, recitado na Sessão publica da Academia Real das Sciencias de Lisboa, em 24 de Junho de 1818" (Historia e Memorias da Academia Real das Sciencias de Lisboa, 1819); José Francisco de Carvalho, "Observações, e Reflexões sobre a vaccina" (Collecção de opusculos sobre a vaccina, 1814); José Feliciano de Castilho, "Conta dada á Instituicção Vaccinica da" Academia Real das Sciencias em sessão de 15 de Fevereiro de 1813", (Collecção de opusculos sobre a vaccina, 1814); José Feliciano de Castilho, "Conta dada á Instituicção Vaccinica da Academia Real das Sciencias em congregação de 15 de Fevereiro de 1813" 
(Collecção de opusculos sobre a vaccina, 1814); "Estabelecimento para a propagaçaõ da vaccina mandada crear na corte do Rio de Janeiro por S.A.R. o Principe Regente Nosso Senhor" (O Investigador Portuguez em Inglaterra, 1812); Justiniano de Mello Franco, "Conta dos trabalhos vaccinicos lida na Sessão Publica da Academia Real das Sciencias de Lisboa aos 24 de Junho de 1816" (Historia e Memorias da Academia Real das Sciencias de Lisboa, 1817); Manual da vacinação (1822); Joaquim Xavier da Silva, "Discurso àcerca da Vaccinação em Portugal, recitado na Sessão publica da Academia Real das Sciencias de Lisboa em 24 de Junho de 1819" (Historia e Memorias da Academia Real das Sciencias de Lisboa, 1820); Francisco Elias Rodrigues da Silveira "Conta dos trabalhos vaccinicos lida na Sessão Pública da Academia Real das Sciencias de Lisboa aos 24 de Junho de 1814" (Historia e Memorias da Academia Real das Sciencias de Lisboa, 1815); Francisco Elias Rodrigues da Silveira "Discurso historico àcerca dos trabalhos da Instituição Vaccinica lido na Sessão publica de 24 de Junho de 1821" (Historia e Memorias da Academia Real das Sciencias de Lisboa, 1823); Wenceslau Soares, "Discurso historico sobre os trabalhos da Instituição Vaccinica, lido na Sessão Publica a Academia Real das Sciencias de Lisboa em 24 de Junho de 1817" (Historia e Memorias da Academia Real das Sciencias de Lisboa, 1818). De Bernardino António Gomes, assinalem-se as publicações, "Conta dada na congregação dos membros da Instituição Vaccinica da Academia Real das Sciencias em 15 de Outubro de 1812" (Collecção de Opusculos sobre a vaccina, 1812); "Recopilaçaõ Historica dos Trabalhos da Instituiçaõ Vaccinica, durante o seu primeiro anno" (Memorias de Mathematica e Physica da Academia Real das Sciencias de Lisboa, 1814), "Conta da Instituição Vaccinica á Academia Real das Sciencias, respectiva ao trimestre de Março, Abril, e Maio" (Collecção de Opusculos sobre a vaccina, 1814), "Conta Annual da Instituição Vaccinica da Academia Real das Sciencias de Lisboa pronunciada na Sessão Publica de 1815" (Historia e Memorias da Academia Real das Sciencias de Lisboa, 1816). Além disso assinale-se a publicação da obra de Eduardo Jenner, justamente o inventor da vacinação contra a varíola, Indagaçã̃ sobre as causas, e effeitos das bexigas de vacca, molestia descoberta em alguns dos condados occidentaes da Inglaterra, particularmente na comarca de Gloucester, e conbecida pelo nome de vaccina, 2. ${ }^{\mathrm{a}}$ ed., 1803. 
Alguns anos depois, na sequência desta dinâmica que se estava a impor no domínio da higiene pública e que culmina nas medidas regulamentares do vintismo, J.P. Freitas Soares publicou em 1818 o Tratado de policia medica, uma obra de higiene pública em que se difundem entre nós as preocupações sanitaristas mais representativas na transição do século XVIII para o século XIX.

Para terminar, parece-nos muito significativo do "estado da arte" no dealbar do século XIX um episódio interessante que se passou na cidade de Coimbra aquando das invasões francesas e onde pela primeira vez foram usadas em Portugal as fumigações de Guyton de Morveau. No jornal Minerva Lusitana retrata-se bem o problema, sendo uma questão no âmbito da higiene pública. Em vários números (entre os números 143 [9 de Setembro de 1809] e 153 [18 de Outubro de 1809]) publica-se naquele periódico Diario que offerecem ao publico os DD. Thomé Rodrigues Sobral e Jeronymo Joaquim de Figueiredo das operações por elles executadas em as vistas de attalhar o contagio, que nesta cidade de Coimbra se começava a experimentar. Trata-se de um texto da autoria de dois professores da Universidade de Coimbra, Tomé Rodrigues Sobral e Jerónimo Joaquim de Figueiredo, que versa os cuidados a ter em consideração perante um eventual contágio de acordo com os preceitos higiénicos da época. Esses cuidados mais avançados no tempo passavam por práticas químicas laboratoriais: as fumigações com cloro. As descrições feitas no texto são muito pormenorizadas, desde a descrição da doença até às metodologias e técnicas utilizadas no tratamento do "contágio", justamente num período em que ainda estava por esclarecer a etiologia das doenças contagiosas. Havia a noção de contágio mas não havia o conhecimento das entidades microbianas que provocavam essa mesma propagação da doença. Havia microscópios, mas Kock e Pasteur ainda tardariam quase meio século.

\section{Conclusões}

No presente artigo efectuámos um balanço de tópicos essenciais da farmácia, dos medicamentos e da saúde em Portugal no início do século XIX, relacionando teoria e prática. Foi um período de convulsões e mudanças 
políticas, económicas e sociais, marcado por alguma inovação científica e por uma pioneira estruturação da saúde pública.

A descoberta de princípios activos medicamentosos, as influências da revolução química de Lavoisier, o surgimento da primeira farmacopeia oficial portuguesa, a vacinação contra a varíola como primeira terapêutica preventiva eficaz, bem como uma descoberta científica - o cinchonino, são em nosso entender, traços distintivos da farmácia, dos medicamentos e da saúde pública em Portugal, no dealbar do século xıx.

\section{Fontes e Bibliografia}

\section{Fontes manuscritas}

—Arquivo da Universidade de Coimbra - A.U.C. - Hospital Real - Administração e contabilidade. Arrendamentos de bens, despesas com obras, regulamentos, pessoal, militares enfermos. Séc. XVIII-XIX - IV-2 ${ }^{\circ} \mathrm{E}-7-5-29$ (Caixa).

-Arquivo da Universidade de Coimbra - A.U.C. - Documentos diversos relativos ao Dispensatório Farmacêutico e Laboratório Químico. Aquisição de drogas, rol de devedores, etc., séc. XVIIIXIX - IV - $2^{\circ} \mathrm{E}-7-4-39$ ).

-Arquivo da Universidade de Coimbra - A.U.C. - Dispensatório Farmacêutico - Documentos de despesa. Despesas de expediente 1780-1847 - IV-2 ${ }^{\circ} \mathrm{E}-7-4-42$ (Caixa).

—Arquivo da Universidade de Coimbra - A.U.C. - Dispensatório Farmacêutico - Aquisição de material e drogas; requerimentos e certidões; despesa de obras - IV-1 $\mathrm{E}-8-3-46$ (Caixa)

\section{Fontes impressas}

- Actas das Congregações da Faculdade de Filosofia(1772-1820). 1978. Coimbra: Arquivo da Universidade.

-Actas das Congregações da Faculdade de Medicina(1772-1820). 1982-1985. 2vols. Coimbra: Arquivo da Universidade.

-Actas dos Conselhos de Decanos (1772-1784) . 1984. vol. 1. Coimbra: Arquivo da Universiade.

-CABRAL, B.J.O.T. - Pharmacopea das Pharmacopeas nacionaes e estrangeiras, 2 vols., Lisboa, Impressão Regia, 1833-1834. 
—CARNEIRO, Heleodoro Jacinto de Araujo - Reflexoens, e observaçoens sobre a pratica da inoculaçaõ da vaccina, e as suas funestas consequencias feitas em Inglaterra, Londres, Mr. Cox, Filho, e Baylis, 1808.

—CARNEIRO, Heleodoro Jacinto Araújo - "Reflexoens e observaçoens sobre a pratica da Inoculaçaõ da vaccina e suas nefastas consequências, feitas em Inglaterra pelo Dr. (...)", O Investigador Portuguez em Inglaterra, 2(6)1811, pp. 173-189; 2(7)1812, pp. 352-377.

—COSTA, Jacinto - Pharmacopea Naval e Castrense, 2 vols., Lisboa, Impressão Regia, 1819.

-FIGUEIREDO, Jerónimo Joaquim de - "Diario de hum doente atacado da febre que grassou nesta Cidade principalmente no bairro da Trindade, da qual passou para o Hospital da Universidade onde foi tratado", Minerva Lusitana, 154,155 e 156, 1809.

-FIGUEIREDO, Jerónimo Joaquim de - Flora pharmaceutica e alimentar portugueza, Lisboa, Typ. da Academia Real das Sciencias, 1825.

-FIGUEIREDO, Jerónimo Joaquim de -"Materia pharmaceutica vegetal portugueza para utilidade da nação, para utilidade da nação, e commodidade dos Boticarios", Jornal de Coimbra, 16(88) 1820, pp. 181-208.

—GOMES, Bernardino António - "Extracto do ensaio sobre o Cinchonino, e sobre sua influencia na virtude da Quina, e de outras cascas", O Investigador Portuguez em Inglaterra, 2(5) 1811, pp. 36-43.

—GOMES, Bernardino António - "Observações Botanico-Medicas sobre algumas Plantas do Brazil", Memorias de Mathematica e Physica da Academia Real das Sciencias de Lisboa, 3(1) 1812, pp. 1-104.

-GOMES, Bernardino António - "Ensaio sobre o Cinchonino e sobre sua influencia na virtude da Quina, e de outras cascas", Memorias de Mathematica e Physica da Academia Real das Sciencias de Lisboa, 3 (1) 1812, pp. 202-217.

— GOMES, Bernardino António - "Conta dada na congregação dos membros da Instituição Vaccinica da Academia Real das Sciencias em 15 de Outubro de 1812", Collecção de Opusculos sobre a vaccina, 2, 1812, pp. 19-24.

— GOMES, Bernardino António - "Recopilaçaõ Historica dos Trabalhos da Instituiçaõ Vaccinica, durante o seu primeiro anno", Memorias de Mathematica e Physica da Academia Real das Sciencias de Lisboa, 3(2) 1814, pp. LXXVI-XCIX.

—GOMES, Bernardino António - "Conta da Instituição Vaccinica á Academia Real das Sciencias, respectiva ao trimestre de Março, Abril, e Maio”, Collecção de Opusculos sobre a vaccina, 13, 1814, pp. 153-183.

—GOMES, Bernardino António - "Conta Annual da Instituição Vaccinica da Academia Real das Sciencias de Lisboa pronunciada na Sessão Publica de 1815”, Historia e Memorias da Academia Real das Sciencias de Lisboa, 4(2) 1816, pp. XXX-LVI.

-JENNER, Eduardo - Indagaçaõ sobre as causas, e effeitos das bexigas de vacca, molestia descoberta em alguns dos condados occidentaes da Inglaterra, particularmente na comarca de Gloucester, e conhecida pelo nome de vaccina, $2^{\mathrm{a}}$ ed., Lisboa, Regia Officina Typographica, 1803.

—LAVOISIER, A. - Traité Élémentaire de Chimie, $2^{\mathrm{a}}$ ed, 2 vols., Paris, Cuchet, Libraire, 1793.

-LEAL, José Francisco - Instituições ou Elementos de Farmácia, Lisboa, Officina de António Gomes, 1792 .

-PAIVA, Manuel Joaquim Henriques de - Curso de medicina theorica e pratica destinado para os cirurgiões que andam embarcados, ou que não estudaram nas Universidades, vol. 1, Lisboa, Typografia Silviana, 1792. 
-PAIVA, Manuel Joaquim Henriques de - Elementos de Chimica e Pharmacia, Lisboa, Of. da Academia Real das Ciências, 1783.

-PAIVA, Manuel Joaquim Henriques de - Farmacopéa Lisbonense, Officina de Filipe da Silva e Azevedo, 1785 .

—PAIVA, Manuel Joaquim Henriques de - Farmacopéa Lisbonense, $2^{\mathrm{a}}$ ed., Lisboa, Officina Patriarcal de João Procopio Correa da Silva, 1802.

-PAIVA, Manuel Joaquim Henriques de-Philosophia chimica, ou verdades fundamentais da Chimica moderna dispostos em nova ordem por A.F. Fourcroy, Lisboa, 1801 ( $2^{\text {a }}$ ed. 1816).

-PAIVA, Manuel Joaquim Henriques de - Preservativo das bexigas ou historia da vaccina, Lisboa, 1801.

- Pharmacopeia Geral para o reino, e domínios de Portugal, 2 vols., Lisboa, Regia Officina Typografica, 1794

- PINTO, Agostinho Albano da Silveira - Codigo Pharmaceutico Lusitano, Coimbra, Imprensa da Universidade, 1835.

-PINTO, António José de Sousa - Pharmacopea chymica, médica, e cirurgica, em que se expoem os remedios simples, e compostos, suas virtudes, preparação, doses ..., Lisboa, Impressão Regia, 1805.

- PINTO, António José de Sousa - Elementos de Pharmacia, Chymica, e Botanica para uso dos principiantes, Lisboa, Impressão Regia, 1805.

-PINTO, António José de Sousa - Materia Medica distribuida em classes e ordens segundo seus effeitos, Lisboa, Impressão Regia, 1813.

—SEABRA, Vicente Coelho - Elementos de Química (1788-1790), ed. fac. sim., Coimbra, Universidade, 1985 .

-SILVEIRA, Francisco Elias Rodrigues da - "Conta dos trabalhos vaccinicos lida na Sessão Pública da Academia Real das Sciencias de Lisboa aos 24 de Junho de 1814”, Historia e Memorias da Academia Real das Sciencias de Lisboa, 4(Parte I) 1815, pp. XXX-XLVI.

—SILVEIRA, Francisco Elias Rodrigues da - "Discurso historico àcerca dos trabalhos da Instituição Vaccinica lido na Sessão publica de 24 de Junho de 1821”, Historia e Memorias da Academia Real das Sciencias de Lisboa, 8(Parte I), 1823, pp. XIX-XXXIV.

-SOARES, José Pinheiro de Freitas - Tratado de policia medica, no qual se comprehendem todas as matterias, que podem servir para organizar hum regimento de policia de saude para o interior do reino de Portugal, Lisboa, Typografia da Academia Real das Sciencias, 1818.

-SOARES, Wenceslau - "Discurso historico sobre os trabalhos da Instituição Vaccinica, lido na Sessão Publica da Academia Real das Sciencias de Lisboa em 24 de Junho de 1817", Historia e Memorias da Academia Real das Sciencias de Lisboa, 6(2) 1818, pp. XXX-LV.

-SOBRAL, Tomé Rodrigues Sobral - "Memoria sobre o principio febrifugo das quinas", Jornal de Coimbra, 14(82)1819, pp. 126-153.

-SOBRAL, Tomé Rodrigues - "Nota sobre os trabalhos em grande que no Laboratorio Chimico da Universidade de Coimbra poderão praticar-se com mais utilidade do Publico, e com maiores vantagens do mesmo Estabelecimento", Jornal de Coimbra, 9(47) 1816, pp. 293-312.

-TAVARES, Francisco - De pharmacologia libellus academicis praelectionibus accomadodatus, Conimbricae, Typographia Academico Regia, 1786. 
-TAVARES, Francisco - Medicamentorum sylloge propriae pharmacological exempla sistens in usum academicarum praelectionum, Conimbricae, Typographia Academico Regia, 1787.

-TAVARES, Francisco - Advertências sobre os abusos, e legitimo uso das águas minerais das Caldas da Rainha, para servir de regulamento aos enfermos que delas têm precisão real, Lisboa, Officina da Academia Real das Sciencias, 1791.

-TAVARES, Francisco - "Descripção de hum feto humano monstruoso nascido em Coimbra no dia 28 de Novembro de 1791", Memorias de Mathematica e Physica da Academia Real das Sciencias de Lisboa, 2, 1799, pp. 296-305.

-TAVARES, Francisco - Resultado das observações feitas no bospital real da inoculação das bexigas nos anos de 1796, 1797 e 1798, Lisboa, Regia Officina Typografica, 1799.

-TAVARES, Francisco - Observações e reflexões sobre o uso proveitoso e saudavel da quina na gôta, Lisboa, Regia Officina Typografica, 1802.

-TAVARES, Francisco - Pharmacologia novis recognita curis, aucta, emendata, et hodierno saeculo accommodata, Conimbricae, Typis Academicis, 1809.

-TAVARES, Francisco - Instruçcões e cautelas práticas sobre a natureza, differentes especies, virtudes em geral e uso legitimo das aguas minerais, principalmente de Caldas; com a notícia daquellas, que são conbecidas em cada uma das provincias do reino de Portugal e o methodo de preparar as aguas artificiaes, Coimbra, Real Imprensa da Universidade, 1810.

-TAVARES, Francisco - Manual dos gotosos e de rheumaticos para uso dos proprios enfermos, Coimbra, Real Imprensa da Universidade, 1810.

-TAVARES, Francisco - Pharmacologia novis recognita curis, aucta, emendata, et hodierno saeculo accommodata, Conimbricae, Typographia Academico Regia, 1829.

\section{Bibliografia}

—AlmeIDA, M. Lopes de — Documentos da Reforma Pombalina, 2 vols, Coimbra, Universidade, 1937-1979.

-BENSAUDE-VINCENT, Bernardette; STENGERS, Isabelle — Histoire de la chimie, Paris, La Découverte, 1993.

—COSTA, A. M. Amorim da. 1986. "Thomé Rodrigues Sobral (1759-1829): a Química ao serviço da comunidade", in História e Desenvolvimento da Ciência em Portugal, vol.1, ob. cit., 1986, pp. 373-401

—DIAS, José Lopes — "Manuel Joaquim Henriques de Paiva, médico e polígrafo luso-brasileiro", Imprensa Médica 18(3)1954, pp. 145-171.

-DONOVAN, Arthur — "The origins of modern chemistry", Osíris 4, 1988, pp. 214-231.

_FILGUEIRAS, Carlos A.L. "The mishaps of peripheral science: the life and work of Manoel Joaquim Henriques de Paiva, Luso-brazilian chemist and physician of the late eighteenth century" Ambix 39(2) 1992, pp. 75-90

- GIFFONI, O. Carneiro — Presença de Manuel Joaquim Henriques de Paiva na Medicina LusoBrasileira do século XVIII, São Paulo, s/ ed, 1954. 
—GOUGH, J.B. — "Lavoisier and the fulfillment of the stahlian revolution", Osíris, 4, 1988, pp. 15-33.

—MARQUES, A.H. Oliveira. 1986. Dicionário de maçonaria portuguesa, vol. 2. Lisboa: Editorial Delta.

—PEREIRA, Ana Leonor; PITA, João Rui — "Liturgia higienista no século XIX. Pistas para um estudo", Revista de História das Ideias, 15, 1993, pp. 437-559.

—PEREIRA, Ana Leonor; PITA, João Rui — "Ciências", MATTOSO, José (Dir.), História de Portugal, vol 5, O Liberalismo (1807-1890), Lisboa, Editorial Estampa, 1993, pp. 652-667.

—PEREIRA, Ana Leonor; PITA, João Rui "Saúde, farmácia e medicamentos no período histórico das invasões francesas". In: SOUSA, Maria Leonor Machado de (coord.) - A Guerra Peninsular: perspectivas multidisciplinares. Actas / Congresso Internacional e Interdisciplinar Evocativo da Guerra Peninsular, integrando o XVII Colóquio de História Militar nos 200 anos das invasões napoleónicas em Portugal, vol. 2, Lisboa, Comissão Portuguesa de História Militar / Centro de Estudos Anglo-Portugueses, 2008, pp. 257-271.

—PESET, Jose Luis — "Terapêutica y medicina preventiva", LAIN ENTRALGO, P., Historia Universal de la Medicina, vol. 5, Barcelona, Salvat Editores, 1984, pp. 99-103.

—PESET, Jose Luís — "El fármaco en la Ilustración y el Romanticismo. In: Historia del medicamento", In: GRACIA GUILLÉN, Diego et al. Barcelona, Ediciones Doyma, 1984, pp. 331-335.

—PITA, João Rui - "O conceito de Farmácia nas 'Instituições ou elementos de Farmácia' de José Francisco Leal - um contributo para a história do medicamento e da ciência farmacêutica portuguesa nos finais do século XVIII", Medicamento, história e sociedade, (Nova série) 1(2)1993, pp. 1-5.

—PITA, João Rui — Farmácia, medicina e saúde pública em Portugal(1772-1836), Coimbra, Minerva, 1996.

—PITA, João Rui - "A quina e outras drogas americanas na produção medicamentosa do Hospital da Universidade de Coimbra nos finais do século XVIII", Mare Liberum - Revista de História dos Mares, 17, Jun. 1999, pp. 197-228.

_PITA, João Rui — "Sanitary normalization in Portugal: pharmacies, pharmacopoeias, medicines and pharmaceutical practices (19-20 Centuries)". In: ABREU, L. (Coord.) - European Health and Social Welfare Policies, Compostela Group of Universities/PhoenixTN, European Thematic Network on Health and Social Welfare Policies/Brno University of Technology-Vutium Press, 2004, pp. 434-453.

—PITA, João Rui — História da Farmácia. $3^{\mathrm{a}}$ ed. Coimbra, MinervaCoimbra, 2007.

-PITA, João Rui; PEREIRA, Ana Leonor - A Europa científica e a farmácia portuguesa na época contemporânea. Estudos do Século XX. 2, 2002, pp. 231-265.

—PITA, João Rui; PEREIRA, Ana Leonor — "Doenças venéreas: do século XVIII ao século XX. Medicamentos de Ribeiro Sanches a Fleming”, In: XVI Colóquio de História Militar. O serviço de saúde militar. Na comemoração do IV centenário dos irmãos hospitaleiros de S. João de Deus em Portugal, vol. 1. Lisboa: Comissão Portuguesa de História Militar, 2007, pp. 359-380. 


\section{Referências}

${ }^{1}$ Este artigo integra-se nas actividades científicas do Grupo de História e Sociologia da Ciência do Centro de Estudos Interdisciplinares do Séc. XX da Universidade de Coimbra-CEIS20.

${ }^{2}$ Pharmacopeia Geral, vol. 1, Lisboa, Regia Officina Typografica, 1794, p. 1.

${ }^{3}$ Idem

${ }^{4}$ idem p. 144.

${ }^{5}$ A terminologia utilizada por Tavares é a de forma "líquida", "mole" e "dura ou seca" (Cfr. Pharmacopeia Geral para o reino, e dominios de Portugal, vol. 1, ob. cit., p. 144).

${ }^{6}$ Cf. Glenn Sonnedecker, "The founding period of the U.S. Pharmacopeia - I. European antecedents", Pharmacy in History, 35 (4), 1993, p. 158.

${ }^{7}$ Idem, Ibidem, p. 158.

${ }^{8}$ Tal como se encontra na obra Pharm. Edimburgensis additamentis aucta ab. Ern. Godofr. Baldinger, Bremae, 1776.

${ }^{9}$ Sobre a primeira farmacopeia oficial portuguesa veja-se na bibliografia final trabalhos publicados pelos autores e em particular a obra de João Rui Pita, Farmácia, medicina e saúde pública em Portugal(1772-1836), Coimbra, Minerva, 1996 donde foram retirados vários destes elementos.

${ }^{10}$ Um estudo muito desenvolvido sobre a botica do Hospital Escolar foi realizado por um dos autores. Muitos dos elementos referidos neste estudo foram obtidos na investigação realizada e podem ser vistos de modo mais completo em João Rui Pita, Farmácia, medicina e saúde pública em Portugal(1772-1836), ob. cit.

${ }^{11}$ Este assunto foi já apresentado pelos autores em: Ana Leonor Pereira; João Rui Pita "Saúde, farmácia e medicamentos no período histórico das invasões francesas”. In: Maria Leonor Machado de Sousa (coord.), A Guerra Peninsular: perspectivas multidisciplinares. Actas / Congresso Internacional e Interdisciplinar Evocativo da Guerra Peninsular, integrando o XVII Colóquio de História Militar nos 200 anos das invasões napoleónicas em Portugal, vol. 2, Lisboa, Comissão Portuguesa de História Militar / Centro de Estudos Anglo-Portugueses, 2008, pp. 257-271.

12 Cf. folha de despesa datada de 31.08.1801 incluída em A.U.C. - Dispensatório Farmacêutico Documentos de despesa. Despesas de expediente 1780-1847 - IV-2E-7-4-42 (Caixa).

${ }^{13}$ Veja-se uma folha onde se discriminam "despezas miudas" em A.U.C. - Dispensatório Farmacêutico - Documentos de despesa. Despesas de expediente 1780-1847 - IV-2E-7-4-42 (Caixa).

${ }^{14}$ Foi dada ordem do pagamento desta dívida em 29.04.1801. Vide documento em A.U.C. Dispensatório Farmacêutico - Aquisição de material e drogas; requerimentos e certidões; despesa de obras - IV-1 ${ }^{\circ} \mathrm{E}-8-3-46$ (Caixa).

${ }^{15}$ Cf. folha de despesa em A.U.C. - Dispensatório Farmacêutico - Documentos de despesa. Despesas de expediente 1780-1847 - IV-2E-7-4-42 (Caixa).

${ }^{16}$ Cf. documento avulso em A.U.C. - Dispensatório Farmacêutico - Documentos de despesa. Despesas de expediente 1780-1847 - IV-2E-7-4-42 (Caixa).

${ }^{17}$ Cf. representação de 17 de Junho de 1809 incluída em A.U.C. - Hospital Real - Administração e contabilidade. Arrendamentos de bens, despesas com obras, regulamentos, pessoal, militares enfermos. Séc. XVIII-XIX - IV-2E-7-5-29 (Caixa).

${ }^{18}$ Cf. representação de Francisco José de Torres em A.U.C. - Hospital Real - Administração e contabilidade. Arrendamentos de bens, despesas com obras, regulamentos, pessoal, militares enfermos. Séc. XVIII-XIX - IV-2 ${ }^{\circ} \mathrm{E}-7-5-29$ (Caixa).

19 Veja-se documento avulso incluído em A.U.C. - Dispensatório Farmacêutico - Aquisição de material e drogas; requerimentos e certidões; despesa de obras - IV-1 ${ }^{\circ} \mathrm{E}-8-3-46$ (Caixa).

20 Eram bastantes as dívidas de particulares ao Dispensatório Farmacêutico. Com frequência encontramos referências do boticário do Dispensatório aos devedores (Cf. A.U.C.-Documentos diversos relativos ao Dispensatório Farmacêutico e Laboratório Químico. Aquisição de drogas, rol de 
devedores, etc., séc. XVIII-XIX - IV-2º-7-4-39).

${ }^{21}$ Vide Relação dos Devedores do Dispensatorio Pharmaceutico, desde o estabelecimento deste até o fim do Anno de 1825 incluída em A.U.C. - Documentos diversos relativos ao Dispensatório Farmacêutico e Laboratório Químico. Aquisição de drogas, rol de devedores, etc., séc. XVIII-XIX - IV$2^{\circ} \mathrm{E}-7-4-39$ (Caixa).

${ }^{22}$ Vide aviso da Junta da Fazenda da Universidade de 21 de Março de 1827, onde se determina que os devedores deveriam liquidar as suas dívidas (Cfr. A.U.C. - Documentos diversos relativos ao Dispensatório Farmacêutico e Laboratório Químico. Aquisição de drogas, rol de devedores, etc., séc. XVIII-XIX - IV -2 ${ }^{\circ} \mathrm{E}-7-4-39$ ).

${ }^{23}$ Ana Leonor Pereira; João Rui Pita, "Liturgia higienista no século XIX. Pistas para um estudo", Revista de História das Ideias, 15, 1993, p. 473.

${ }^{24}$ Idem, Ibidem, p. 462.

${ }^{25}$ Idem, Ibidem, p. 463. 